\title{
Kurumsal Bilgi Yönetimi Modeli (EKMM) ; İmalat Sektöründe Faaliyet Gösteren Bir İşletmede Uygulama Örneği
}

\author{
${ }^{*}$ Seher Arslankaya, ${ }^{2}$ Cem Özkurt ve ${ }^{1}$ Selin Dökme \\ ${ }^{1}$ Sakarya Üniversitesi, Mühendislik Fakültesi, Endüstri Mühendisliği, Sakarya, Türkiye \\ ${ }^{2}$ Sakarya Uygulamalı Bilimler Üniversitesi, Sakarya, Türkiye
}

\section{Özet}

Günümüz koşullarında kurumlar için rekabet ve mükemmelliyetçilik ve bu doğrultuda müşteri memnuniyeti ön plana çıkmaktadır. Bu kapsamda kurumların rekabette üstünlük, süreçlerde mükemmellik ve müşterinin memnuniyetini sağlaması noktasında bilgi kavramı önem kazanmaktadır. Gelişen ve gelişmesi istenen tüm süreçlerin bilgi temelinde oluştuğu kabul edilmektedir. Bu doğrultuda ne bildiğini bilmeyen ve sahip olduğu bilgiyi yönetemeyen kurumların geriye doğru gittiği gözlemlenmektedir. Bütün bunların neticesinde büyük ve değerli olan bilginin elde edilmesi, saklanması ve yönetilmesi kurumlar açısından zaruri bir ihtiyaç haline gelmektedir. Kurum içindeki süreçlerde süreçlerin kişiden bağımsız hale gelmesi, bilgi akışının şeffaf halde olması, mevcutta tüm kademelerde olan bilgiye hakim olunması ve kurum performansının iyileştirilmesi bilgi yönetiminin temelleri arasındadır. Bu kapsamda kurumsal içerikli bilginin yönetilebilmesi için birçok bilgi yönetim modeli geliştirilmiştir. Bu çalışmada imalat sektöründe faaliyet gösteren bir işletmenin tüm kademeleri için Kurumsal Bilgi Yönetimi Modeli (Bilgi Kulesi) uygulanmıştır. Uygulama sonuçları kurum için değerlendirilip puanlandırılmış ve mevcut durum ortaya konmuştur. Ayrıca firma için eksik ve / veya gelişmeye açık görülen kısımlara öneriler sunulmuştur.

Anahtar Kelimeler: Bilgi, Bilgi Yönetimi, Kurumsal Bilgi Yönetimi Modeli

\begin{abstract}
In today's conditions, competition, perfectionism and customer satisfaction come to the fore for enterprises. In this context, the concept of knowledge gains importance in terms of enterprises' competitive advantage, process excellence and customer satisfaction. It is accepted that all developing and desired to developing processes are formed on the basis of knowledge. In this direction, it is observed that enterprises that do not know what they know and cannot manage their knowledge go backwards. As a result of all these, obtaining, storing and managing large and valuable knowledge becomes an indispensable requirement for enterprises. Some of the basic concepts knowledge management are that the processes within the enterprise become independent from the person, the knowledge flow is transparent, the knowledge currently available at all levels and the improvement of the enterprise performance. In this context, many knowledge management models have been developed to manage enterprise knowledge. In this study, Enterprise Knowledge Management Model (Knowledge Tower) has been applied for all levels of an enterprise operating in the manufacturing sector. Implementation results were evaluated and scored for the enterprise and the current situation was revealed. In addition, suggestions were made for the parts that were deemed to be deficient and / or open to improvement.
\end{abstract}

Key Words: Knowledge, Enterprise Knowledge Management

*Seher Arslankaya: Adres: Mühendislik Fakültesi, Endüstri Mühendisliği Bölümü Sakarya Üniversitesi, 54187, Sakarya TURKEY. E-posta adresi: aseher@ sakarya.edu.tr, Telefon: +902642955686 


\section{Giriş}

Bilgi kavramı günlük hayatımızda sıklıkla kullandığımız fakat tanımlamak konusunda zorlandığımız kavramlardan biridir. Binlerce yıl öncesinde insanlığın temelini oluşturmuştur. Bilgi, tecrübe veya çalışma yoluyla kazanılmış anlayıştır. Aynı zamanda, gerçeklerin birikimi veya kuraldır. Bilgi spesifiktir, bir problem alanından diğerine transfer edilemez, belli bir zamanda kullanılır ve daha sonra o bilgiye ihtiyaç duyulmayabilir. Bilgi, başarılı deneyimlerle gelişir ve sonra da bu tecrübe uzmanlığa dönüşür [1]. Diğer yandan bilgi, işletmeler bilgi temelinde rekabet etmekte, ürünler ve hizmetler çok önemli bilgi bileşenleri ile günden güne daha değerli olmakta ve hayat boyu öğrenme, kurumların bir gerçeği haline gelmektedir [2].

Veri ve enformasyon kavramları, bilgi kavramı ile yakından ilişkilidir. Veri; bilgiyi elde etmeye yönelik olan ve işlenmemiş ham bir malzeme, dağınık haldeki bir topluluktur [3]. Enformasyonda ilgili ve ilişkili verilerin, belli bir amaç doğrultusunda bir araya getirilen veriler olduğu görülmektedir. Veriler anlam kazanarak enformasyona temel oluştururlar. Entellektüel sermaye, bilgi birikimi yönetimi gibi kavramlar giderek yaygınlaşırken, sürekli değişim içinde olan dijital çağa ve iş hayatındaki rekabet ortamına ayak uydurmak için artık bilgiyi en pragmatik yollarla, en verimli şekilde kullanmak bir zorunluluk haline gelmiştir [4]. Bilginin muhafaza edilebilmesi, doğru yönlendirilmesi, ihtiyaç halinde kullanılabilmesi ve üretkenliğin arttırılabilmesi adına "Bilgi Yönetimi” kavramı ortaya çıkmıştır.

Bilgi yönetimi, bir organizasyonun misyonunu gerçekleştirmek veya amacına ulaşmak ve aldığı kararları en etkili biçimde kullanmak için üretme ve paylaşma açısından bilgiyi kontrol altına alma faaliyeti şeklinde tanımlanmaktadır [5]. Bir organizasyonun bilgisinin üretimi, depolanması, düzenlenmesi, erişimi ve dağıtımını kapsayan kısaca; kurumun bilgi kaynaklarının düzenlenmesi, etkin yönetimi ve kullanımını 'bilgi yönetimi' olarak ifade edilmektedir [6].

\section{Malzeme ve Yöntem}

Bilginin alınması, saklanması ve yönetilmesi süreci ile ilgili bir çok model bulunmaktadır. Ortaya atılan modeller genel olarak incelendiğinde hepsinin bilgi yönetim süreçlerinin farkı boyutları üzerinde durmuşlardı ve bu boyutlarla ilgili farklı görüşler ortaya atmışlardır. [7]

Bunlara birkaç örnek verecek olursak; EvEr bilgi yönetim modeline göre; modelin mantığı sürekli ilerleme, sonuçların uyumu ve bilgi yoğun kültür anlayışından oluşmaktadır. Bu model kolaylayıcılar, stratejiler, mimari, organizasyonel yapı ve değerlendirmeler olarak 5 aşamadan oluşmaktadır [8].

Bilgi çeşitlerini sınıflamada temel olarak kabul edilen SECI modelini incelediğimizde bilginin örtülü bilgi (tacit knowledge) ve açık bilgi (explicit knowledge) olarak adlandırılan iki türünden söz edilmektedir. Buna göre model sosyalleşme (örtülü bilgiden örtülü bilgiye), birleştirme (açı bilgiden açık bilgiye), dışsallaştırma (örtülü bilgiden açık bilgiye) ve içselleştirme (açık bilgiden örtülü bilgiye) den oluşur. [9] 
Yapılan uygulama çalışmasında ele alınan bilgi yönetimi "Kurumsal Bilgi Yönetimi (Bilgi Kulesi)" modelidir. Model, 9 modül kapsamında belirlenmiş olan 22 ana kriter etrafında oluşturulan alt kriterlerin kurum açısından değerlendirilmesi sonucu ile saptanmaktadır. Şekil 1.' de görüldüğü üzere model kapsamında 9 modül düzeyinde ölçüm gerçekleştirilecektir.

Şekil 1: Bilgi Kulesi Modeli

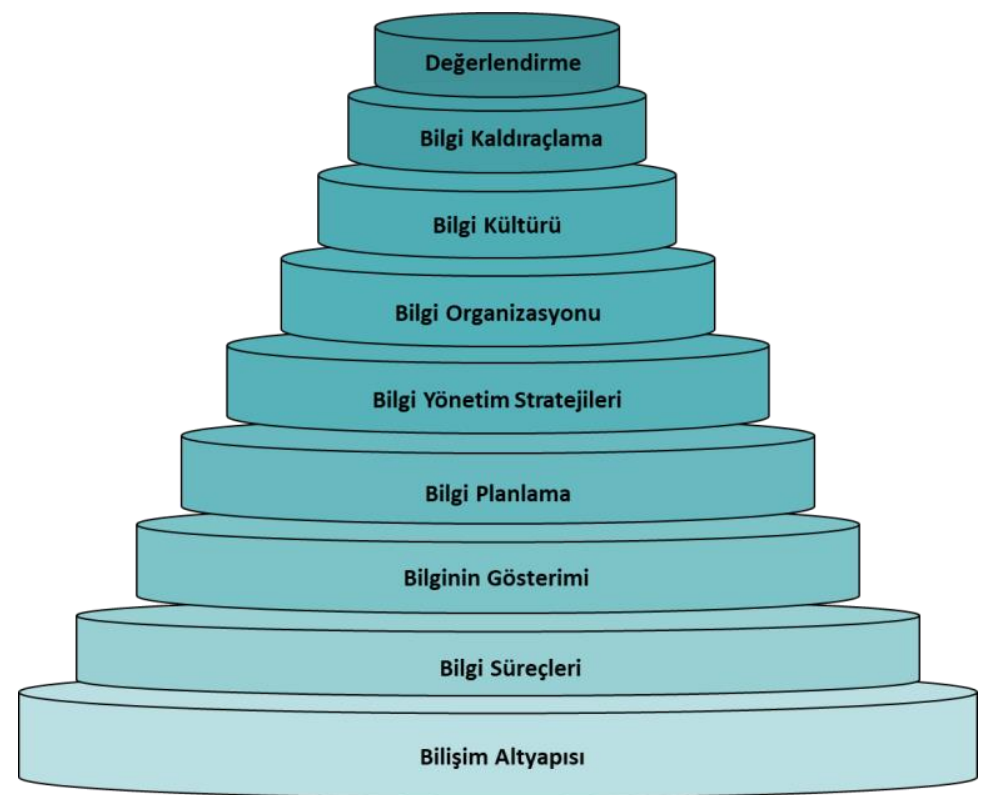

\section{1. Ölçme ve Değerlendirme}

Modelin 9 modülü çerçevesinde, bu düzeylerdeki bilgiyi kullanma ve değerlendirebilme yeteneklerini ölçmek için aşağıda bir örneği verilen 22 adet kriter baz alınarak ve her bir kriterin de stratejik, taktik ve operasyonel seviyeler için belirlenmiş olan alt kriterleri kullanarak ölçümler gerçekleştirilecektir.

Yapılan ölçümlerde tüm değerlendirmeler toplam 1000 puan üzerinden gerçekleştirilecektir. Modelin her bileşeni için her kriter ve alt kriter bazında bir puan skalası bulunmaktadır. Tablo 2'de verildiği gibi modelin her bileşenini stratejik, taktik ve operasyonel açıdan alabilecekleri puan oluşturulmuştur. Belirlenen bu puanlar alt kriterlere dağıtılarak beklenen ve gerçekte var olan puanların karşılaştırması yapılmakta ve işletmenin 1000 puan üzerinden alabileceği puan belirlenmektedir. Bilgi yönetimin her bir modülünü etkileyen bu kriterler 3 seviyede incelenmektedir. Bunun nedeni ise kurum bazında en alt tabakadan en üst tabakaya kadar herkesin ortak katkısını hedeflemesidir [10]. 


\begin{tabular}{|c|c|c|c|}
\hline No & Model Elemanı & İlgili Kriterler & Açıklama \\
\hline 1 & $\begin{array}{l}\text { Bilişim Altyapısının } \\
\text { Oluşturulması }\end{array}$ & $\begin{array}{l}5,9,11,12,15,16,17,1 \\
8,19\end{array}$ & $\begin{array}{l}\text { Bu model elemanı ile kurumsal bilgi yönetimi aktivitelerinin sağlıklı bir sekilde } \\
\text { geliştirilmesi için gerekli olan bilişim alt yapısının durumu değerlendirilir ve } \\
\text { eksikliklere işaret edilir }\end{array}$ \\
\hline 2 & $\begin{array}{l}\text { Bilgi Yönetim Süreçlerinin } \\
\text { Tasarlanması ve Uygulanması }\end{array}$ & $\begin{array}{l}1,2,3,4,9,10,13,1,15 \\
16,17,18,19,21\end{array}$ & $\begin{array}{l}\text { Bilgi süreçleri, bilgi arama, izleme, elde etme ve ortaya çıkarma, bilgi üretimi ve } \\
\text { kullanımı, bilginin depolanması, güncellemesi, kontrol edilmesi vb. Gibi aktivitelerin } \\
\text { ne kadar sağlıklı yapıldığ } 1 \text { değerlendirilir ve eksikliklere işaret edilir. }\end{array}$ \\
\hline 3 & $\begin{array}{l}\text { Bilgi Gösterim Yöntemlerinin } \\
\text { Kullanılması }\end{array}$ & $\begin{array}{c}1,2,15,16 \\
17,18,19,21\end{array}$ & $\begin{array}{l}\text { Bilgi gösterimi yöntemleri, raporlama, bilginin arşivlenmesi vb. Gibi unsurların } \\
\text { değerlendirilir ve eksikliklere işaret edilir. }\end{array}$ \\
\hline 4 & $\begin{array}{l}\text { Kurumsal Bilgi ve } \\
\text { Kullanımının Planlanması }\end{array}$ & $\begin{array}{c}3,4,9,10,15 \\
16,17,18,19,22\end{array}$ & $\begin{array}{l}\text { Bilginin doğru yerde doğru zamanda ve doğru kişilerle kullanılmasını sağlamak } \\
\text { amacıyla oluşturulan planlar değerlendirilir ve eksikliklere işaret edilir. }\end{array}$ \\
\hline 5 & $\begin{array}{l}\text { Bilgi Yönetimi Stratejilerinin } \\
\text { Oluşturulması ve } \\
\text { Uygulanması }\end{array}$ & $\begin{array}{c}8,9,13,14,15 \\
16,17,18,19,20,22\end{array}$ & $\begin{array}{l}\text { Kurumsal bilgilerin en etkin sekilde değerlendirilmesini sağlayacak stratejilerin } \\
\text { uygulaması değerlendirilir ve eksikliklere işaret edilir. }\end{array}$ \\
\hline 6 & Bilgi Ağırlıklı Örgütlenme & $\begin{array}{l}6,9,12,15,16,17,18 \\
19\end{array}$ & $\begin{array}{l}\text { Örgütlenme fonksiyonunun yerine getirilebilmesi için amaçların, faaliyetlerin ve } \\
\text { yapılacak işlerin belirlenmesi sorumlulukların doğru atanmış olması vb. Gibi unsurlar } \\
\text { değerlendirilir ve eksikliklere işaret edilir. }\end{array}$ \\
\hline 7 & $\begin{array}{l}\text { Bilgi Kültürünün } \\
\text { Oluşturulması }\end{array}$ & $\begin{array}{l}3,7,9,13,14,15 \\
16,17,18,19,22\end{array}$ & $\begin{array}{l}\text { Organizasyon her düzeyinde çalışanların bütün davranışlarını, bilgiye dayandırmaları, } \\
\text { bilginin gücüne inanmaları ve bilgilerini sürekli yenilemek ve güncellemek uğraşısı } \\
\text { içinde birbirleri ile paylaştıkları ortamda etkin, verimli ve güvenilir bilgi yönetimi } \\
\text { anlayışının oluşturulması değerlendirilir ve eksikliklere işaret edilir. }\end{array}$ \\
\hline 8 & $\begin{array}{l}\text { Bilgi Kaldıraçlama ve } \\
\text { Yönlendirme }\end{array}$ & $\begin{array}{l}4,13,14,15,16 \\
17,18,19,20\end{array}$ & $\begin{array}{l}\text { Bireylerin ihtiyacı olan bilgileri kendilerine sağlayarak bilgi ve deneyim artırıcı } \\
\text { faaliyetler değerlendirilir ve eksikliklere işaret edilir. }\end{array}$ \\
\hline 9 & $\begin{array}{l}\text { Bilgi Yönetimi Aktivitelerinin } \\
\text { Değerlendirilmesi }\end{array}$ & $15,16,17,18,19$ & $\begin{array}{l}\text { Kurum içinde etkin bilgi yönetimi yapılıp yapılmadığı ve bir kurumun sahip olduğu } \\
\text { kurumsal ve bireysel entellektüel sermayenin pozitif değer oluşturacak sekilde } \\
\text { kullanılması değerlendirilir ve eksikliklere işaret edilir. }\end{array}$ \\
\hline
\end{tabular}

Tablo 1: Kriter- Model Elemanı Ilişkileri [1]

Belirlenmiş olan kriterlerin de alt kriterleri bulunmakdır. Tüm modüllerin alt kriterleri ve değerlendirme puanları belirlenmiştir. Yapılan çalışma kapsamında ilgili kurumda anket doğrultusunda görüşmeler gerçekleştirilmiş ve kriterler tek tek ilgili katılımcılara sorulmuştur. Alınan cevaplar ile alt kriter puanları çarpılmış ; stratejik, taktik ve operasyonel seviye puanları elde edilmiştir. Bu üç seviyede elde edilen puanlar toplanarak ana kriter puanları elde edilmiş, ana kriterlere ait puanlar da çalışmanın başında belirlenmiş olan yüzde değerleri ile çarpılmış ve ilgili modüle ait puan elde edilmiştir. 


\begin{tabular}{|c|c|c|c|c|}
\hline Bilgi Yönetimi Unsuru & $\begin{array}{c}\text { Operasyonel } \\
\text { Düzey }\end{array}$ & $\begin{array}{l}\text { Taktik } \\
\text { Düzey }\end{array}$ & $\begin{array}{c}\text { Stratejik } \\
\text { Düzey }\end{array}$ & Toplam \\
\hline 1-Bilişim Altyapısı & 45 & 45 & 60 & 150 \\
\hline 2-Bilgi Yönetimi Süreçlerinin Tasarlanması Ve Uygulanması & 35 & 40 & 50 & 125 \\
\hline 3- Bilgi Gösterimi Yöntemlerinin Kullanılması Ve Ekinliği & 25 & 30 & 35 & 90 \\
\hline 4-Kurumsal Bilgi Ve Kullanımının Planlanması & 40 & 40 & 30 & 110 \\
\hline 5-Bilgi Yönetimi Stratejilerinin Oluşturulması Ve Uygulanması & 55 & 35 & 30 & 120 \\
\hline 6- Kurumsal Olarak Bilgi Ağırlıklı Örgütlenme & 40 & 40 & 30 & 110 \\
\hline 7-Bilgi Kültürünün Oluşturulması Ve Korunması & 40 & 30 & 30 & 100 \\
\hline 8-Kurumsal Bilgi Kaldıraçlama Ve Yönlendirme & 30 & 35 & 30 & 95 \\
\hline 9-Bilgi Yönetimi Uygulamalarının Kurum Içinde Değerlendirilmesi & 40 & 30 & 30 & 100 \\
\hline Toplam & 350 & 325 & 325 & 1000 \\
\hline
\end{tabular}

Tablo 2: Bilgi Kulesi Değerlendirme Puan Dağılımı [1]

\section{Sonuçlar}

Yapılan çalışmada Bilgi Kulesi Modeli çerçevesinde imalat sektöründe faaliyet gösteren $\mathrm{X}$ işletmesinde anket uygulanmış ve elde edilen verilerin özet hali tabloda sunulmuştur.

\begin{tabular}{|c|c|c|c|c|c|c|c|c|c|c|c|c|}
\hline Kriterler & $\begin{array}{c}\text { Anket } \\
\text { Maxkriter } \\
\text { Puanı }\end{array}$ & $\begin{array}{c}\text { Maxkriter } \\
\text { Puanı }\end{array}$ & 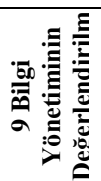 & 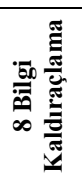 & 总 & 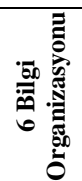 & 的泀离 & 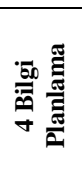 & 可高 & 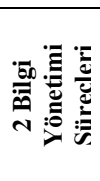 & 恶畜 & 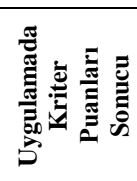 \\
\hline 1 & 19 & 1000 & & & & & & & 7,09 & 5,15 & & 644,1167 \\
\hline 2 & 20 & 1000 & & & & & & & 5,86 & 4,80 & & 533,0667 \\
\hline 3 & 29 & 1000 & & & 4,90 & & & 5,98 & & 4,90 & & 544,0167 \\
\hline 4 & 30 & 1000 & & 5,77 & & & & 6,34 & & 5,19 & & 576,55 \\
\hline 5 & 16 & 1000 & & & & & & & & & 4,55 & 284,3 \\
\hline 6 & 14 & 1000 & & & & 8,97 & & & & & & 640,8667 \\
\hline 7 & 9 & 1000 & & & 4,45 & & & & & & & 494,0833 \\
\hline 8 & 11 & 1000 & & & & & 6,39 & & & & & 580,7667 \\
\hline 9 & 69 & 1000 & & & 5,00 & 7,22 & 6,11 & 6,11 & & 5,00 & 8,89 & 555,7333 \\
\hline 10 & 20 & 1000 & & & & & & 6,56 & & 5,37 & & 596,6333 \\
\hline 11 & 22 & 1000 & & & & & & & & & 13,79 & 626,7167 \\
\hline 12 & 30 & 1000 & & & & 8,64 & & & & & 9,87 & 617,15 \\
\hline 13 & 39 & 1000 & & 6,01 & 5,41 & & 6,61 & & & 5,41 & & 600,8667 \\
\hline 14 & 39 & 1000 & & 5,88 & 5,30 & & 6,47 & & & 5,30 & & 588,3333 \\
\hline 15 & 111 & 1000 & 9,95 & 4,97 & 4,48 & 6,96 & 5,47 & 5,47 & 5,47 & 4,48 & 7,96 & 497,3167 \\
\hline 16 & 112 & 1000 & 11,51 & 6,33 & 5,18 & 8,06 & 6,33 & 6,33 & 6,33 & 5,18 & 9,21 & 575,5333 \\
\hline 17 & 112 & 1000 & 10,30 & 5,67 & 4,64 & 7,21 & 5,67 & 5,67 & 5,67 & 4,64 & 8,24 & 515,0167 \\
\hline 18 & 111 & 1000 & 10,60 & 5,83 & 4,77 & 6,89 & 5,83 & 5,83 & 5,83 & 4,77 & 8,48 & 530,2213 \\
\hline 19 & 112 & 1000 & 11,52 & 6,34 & 5,18 & 8,06 & 6,34 & 6,34 & 6,34 & 5,18 & 9,21 & 575,9333 \\
\hline 20 & 22 & 1000 & & 5,60 & & & 5,60 & & & & & 509,1333 \\
\hline 21 & 22 & 1000 & & & & & & & 7,63 & 5,28 & & 586,9 \\
\hline 22 & 31 & 1000 & & & 6,01 & & 6,01 & 6,61 & & & & 601,2667 \\
\hline Toplam & & & 53,88 & 55,46 & 55,31 & 62,02 & 66,83 & 61,25 & 50,21 & 70,64 & 80,21 & \\
\hline
\end{tabular}

Tablo 3: Genel Sonuçlar

\subsection{Bilişim Altyapısının Oluşturulması}

Bu model elemanı ile kurumsal bilgi yönetimi aktivitelerinin sağlıklı bir şekilde geliştirilmesi için gerekli olan bilişim alt yapısının durumu değerlendirilir ve eksikliklere işaret edilir. Anket sonucunda görüldüğü üzere; Bilişim Alt Yapısının Oluşturulması Model elemanına göre firma 
toplamda 150 puan üzerinden 80.21 puan almaktadır. Alınması gereken puanın \% 53,47 sine ulaşıldığını görmekteyiz. Bunun temel sebeplerinden biri firmanın bilişim alt yapısı oluşturma sürecinde olmasıdır. Henüz kurum genelinde işlerlik kazanmamış ama tüm ekip tarafından benimsenerek temelinin oluşturulmaya çalışılmasıdır.

\subsection{Bilgi Yönetimi Süreçleri}

$\mathrm{Bu}$ model elemanında; bilgi süreçleri, bilgi arama, izleme, elde etme ve ortaya çıkarma, bilgi üretimi ve kullanımı, bilgi depolama, bilgi güncelleme, bilgi transferi ve paylaşımı, bilginin kontrol edilmesi vb. gibi aktivitelerin ne kadar sağlıklı yapıldığı değerlendirilir ve eksikliklere işaret edilir.

Anket sonucunda görüldügü üzere; Bilişim Yönetim Süreçleri Model elemanına göre firma toplamda 125 puan üzerinden 70,64 puan almaktadır. \%56,51' lik bir sonuç almış olan firmanın bu sonuca ulaşmasının sebebi, kök nedene bakıldığında yine sistemin kurulum aşamasında olmasıdır. Bunun yanında kurum içerisinde kütürün henüz oturmamış olmaması nedeniyle, çalışanlar arasında kurumsal bilginin kullanımı, depolanması ve paylaşımına yönelik davranış henüz oluşmamıştır. Oluşturulmuş olan prosedürler ve kullanılmakta olan kurumsal portal ile bilgi yönetiminin çalışma sürecinde işlediğini görmekteyiz. Burada firmaya yapılacak olan tavsiye; henüz tüm kurumun tamamına yayılmamış olan kurumsal portalın tüm çalışanlar tarafından kullanılmasının sağlanması ve böylece kurumsal bilginin herkes tarafından ulaşılabilir, kullanılabilir hale gelmesinin sağlanmasıdır. Bu aşamada kurum genelinde tüm çalışanlara verilecek olan eğitimler de gelişime destek olacaktır.

\subsection{Bilgi Gösterimi}

$\mathrm{Bu}$ model elemanında; bilgi gösterimi yöntemleri, raporlama standartları, bilgisayar da bilginin arşivlenmesi vb. gibi unsurların değerlendirilir ve eksikliklere işaret edilir.

Anket sonucunda görüldüğü üzere; Bilgi Gösterimi Model elemanına göre firma toplamda 90 puan üzerinden 50,21 puan almaktadır. Dolayısıyla \%55.78 lik bir değerlendirme puanına ulaşmaktadır.

\subsection{Bilgi Planlama}

$\mathrm{Bu}$ model elemanında; bilginin doğru yerde doğru zamanda ve doğru kişilerle kullanılmasını sağlamak amaciyla oluşturulan planlar değerlendirilir ve eksikliklere işaret edilir.

Bu alanda, 110 puan üzerinden 61,25 puan alınmış ve \%55,68'lik bir sonuç elde edilmiştir. Burada kurumun gelişimi için yönetici kademesinde eğitimler yolu ile bir bilinç oluşturulmal1, oluşturulmuş olan bilinç geliştirilmelidir. Böylece sistemin doğru işlemesi ile ilgili takımların yönlendirilmesi geliştirilecektir.

\subsection{Bilgi Stratejileri}

$\mathrm{Bu}$ model elemanında; kurumsal bilgilerin en etkin şekilde değerlendirilmesini sağlayacak stratejilerin uygulaması değerlendirilir ve eksikliklere işaret edilir.

Anket sonucunda görüldüğü üzere; Bilgi Stratejileri Model elemanına göre firma toplamda 120 puan üzerinden 66,83 puan almaktadır. Dolayısıyla \%55.69 luk bir değerlendirme puanına 
ulaşmaktadır. Bu alanda elde edilmiş olan puanın temelinde, kurumun Ar-Ge çalışmalarına vermiş olduğu destek bulunmaktadır. Kurulmuş olan Ar-Ge merkezi ve yapılan patent çalışmaları ile desteklenen süreç, alınan puana sebep olmuştur. Geliştirilmesi adına; yapılan çalışmalara destek verilmesi gerekmektedir. Başta Ar-Ge personelleri olmak üzere, tüm çalışanların yenilikler üreterek gelişim sürecine katılması sağlanmalıdır. Bu da kurum içerisinde eğitim ve gelişim faaliyetleri ile desteklenmelidir.

\subsection{Bilgi Stratejileri}

$\mathrm{Bu}$ model elemanında; örgütlenme fonksiyonunun yerine getirilebilmesi için amaçların, faaliyetlerin ve yapılacak işlerin belirlenmesi sorumlulukların doğru atanmış olması vb. gibi unsurlar değerlendirilir ve eksikliklere işaret edilir

Anket sonucunda görüldügü üzere; Bilgi Organizasyonu Model elemanına göre firma toplamda 110 puan üzerinden 62,02 puan almaktadır. Dolayısıyla \%56,38 lik bir değerlendirme puanına ulaşmaktadır. Burada yine temelde eğitim faaliyetleri aracılığıyla yönetici kademesinin geliştirilmesi bulunmaktadır.

\subsection{Bilgi Kültürü}

$\mathrm{Bu}$ model elemanında; organizasyon her düzeyinde çalışanların bütün davranışlarını, bilgiye dayandırmaları, bilginin gücüne inanmaları ve bilgilerini sürekli yenilemek ve güncellemek uğraşısı içinde birbirleri ile paylaştıkları ortamda etkin, verimli ve güvenilir bilgi yönetimi anlayışının oluşturulması değerlendirilir ve eksikliklere işaret edilir.

Anket sonuçlarına göre; Bilgi Kültürü Model elemanına göre firma toplamda 100 puan üzerinden 55,31 lik bir değerlendirme puanına ulaşmaktadır. Bu alanda elde edilen puanın temelinde kurum içerisinde temeli atılmış ve faaliyet göstermekte olan Akademi kuruluşu bulunmaktadır. Gelişiminde de yine akademi faaliyetleri rol oynayacaktır.

\subsection{Bilgi Kaldıraçlama}

$\mathrm{Bu}$ model elemanında; bireylerin ihtiyacı olan bilgileri kendilerine sağlayarak bilgi ve deneyim artırıcı faaliyetler değerlendirilir ve eksikliklere işaret edilir. Anket sonuçlarına göre; Bilgi Kültürü Model elemanına göre firma toplamda 95 puan üzerinden 52,39 puan almaktadır. Dolayısıyla $\% 55,14$ lük bir değerlendirme puanına ulaşmaktadır.

\subsection{Bilgi Yönetimi Aktivitelerinin Değerlendirilmesi}

Bu model elemanında; kurum içinde etkin bilgi yönetimi yapılıp yapılmadığı ve bir kurumun sahip olduğu kurumsal ve bireysel entelektüel sermayenin pozitif değer oluşturacak şekilde kullanılması değerlendirilir ve eksikliklere işaret edilir.

Anket sonuçlarına göre; Bilgi Yönetimi Aktivitelerinin Değerlendirilmesi Model elemanına göre firma toplamda 100 puan üzerinden 553,88 puan almaktadır. Burada firmanın yönetici yetiştirme projesi ile geliştirdiği terfi mekanizması önemli rol oynamaktadır. Bunun yanında personellerin inisiyatif alabilmesi ve bu durumlarda yöneticileri tarafından desteklenmesi sürece katkı sağlamaktadır. Aynı zamanda daha önce de bahsedilmiş olan Ar-Ge merkezi kapsamında yürütülen 
çalışmalar önemli rol oynamaktadır. Kurumun bu alanı geliştirebilmesi için eğitim ve gelişim faaliyetlerine özen göstermesi, hem teknik hem bireysel anlamda çalışanların gelişimine katkıda bulunmas1 gerekmektedir.

\section{Sonuçlar}

Bilgi günümüz dünyasınıın en önemli varlığıdır. Kurumların rekabet piyasasında varlığını sürdürebilmesi için bilgi elde edebilmesi, elde edilen bilgiyi işleyerek saklayabilmesi ve ihtiyaç halinde kullanabilmesi gerekmektedir. Kayıtlı ya da kayıtsız tüm bilginin kurumsal bilginin bir parçası olduğu kabul edilerek yönetilmesi ilgili kuruma başarıyı getirecek olan en önemli ölçütlerden biridir. Bilginin yönetilmesi, entelektüel sermayenin ne şekilde ve hangi oranda kullanıldığının bilinmesini beraberinde getirecektir.

Firma; model elemanları bazında bakıldığında; 1000 puanlık bir değerlendirmede 552,74 puan almış ve \% 55,27 başarı göstermiştir. Genele bakıldığında, kurumun bu yüzdeye ulaşmasında, dijitalleşme çalışmaları ve İK bünyesinde yürütülen organizaysonel gelişim ve eğitim çalışmaları etkilidir. Daha yüksek yüzdelere ulaşması konusunda eğitimler ile kültürün yaygınlaştırılmasını desteklemesi önemli bir noktadır.

\section{Ekler}

Şekil 1: Bilgi Kulesi Modeli

Tablo 1: Kriter- Model Elemanı Ilişkileri

Tablo 2: Bilgi Kulesi Değerlendirme Puan Dağılımı

Tablo 3: Genel Sonuçlar

\section{Referanslar}

[1] Aksoy, E. (2001). Bilgi Yönetimi ve Uygulama Adımları. İstanbul: Yüksek Lisans Tezi, Marmara Üniversitesi.

[2] Arslankaya, S. (2007). Kurumsal Bilgi Yönetimi Modeli. Doktora Tezi, Sakarya Üniversitesi

[3] Barclay, R. O., \& Murray, P. C. (1997). What İs Knowledge Management. Knowledge Praxis Knowledge Management Associates.

[4] Bilgi Yönetimi. https://www.kigem.com/: https://www.kigem.com/bilgi-yonetimi.html. Erişim Tarihi : 10.05.2019

[5] Clark, D. (2004). Understanding and Performance. http://www.nwlink.com/ donclark/performance/understanding.html. 
[6] Fırat, G. (2013). Kurumsal Bilgi Yönetimi. İstanbul: Yüksek Lisans Tezi, Beykent Üniversitesi.

[7] Kılıç, B. (2018). Bilim, Bilişim, BÖTE Arşiv. Veri Nedir? Veritabanı Nedir? Arasındaki Farklar Nelerdir?: https://www.botearsiv.com/veri-nedir-veritabani-nedir-arasindaki-farklarnelerdir/ . Erişim Tarihi: 14.05.2019

[8] Mertins, K., Heising, P., \& Vorbeck, J. (2005). Knowledge Management: Concepts and Best Practice. Springer, 5-6.

[9] Odabaş, H. (2005). Kurumsal Bilgi Yönetimi. Ankara: Ankara Üniversitesi.

[10] Özdemirci, F. (2001). Belge Üretimi ve Kurumsal Bilgi Yönetimi . 21. Yüzyıla Girerken Enformasyon Olgusu Sempozyumu, (s. 179-186). Hatay.

[11] Sotirofski, K., \& Güçlü, N. (2006). Bilgi Yönetimi. Türk Eğitim Bilimleri Dergisi, 351371.

[12] Yılmaz, M. (2009). Enformasyon ve Bilgi Kavramları Bağlamında Enformasyon Yönetimi ve Bilgi Yönetimi. Ankara Üniversitesi Dil ve Tarih-Coğrafya Fakültesi Dergisi, 95-118. 